\title{
Climate change implications for stand yields and soil expectation values: A northern Saskatchewan case study
}

\author{
by Mark Johnston ${ }^{1}$ and Tim Williamson²
}

\begin{abstract}
We explore the effects of climate change on future stand yields and future area burned, and integrate these to determine future Soil Expectation Values (SEV) for white spruce (Picea glauca (Moench) Voss) in central Saskatchewan. The results suggest that under most future scenarios, stand productivity increases, but decreases under extreme drought. However, projected increases in area burned offset these productivity increases. Under high levels of future area burned, SEV is lower than current values, resulting in a negative economic impact. We also find that the optimal economic rotation age under future climate is lower than that under present climatic conditions.
\end{abstract}

Key words: climate change impacts, forest management, stand yield effects, forest ecosystem models, $\mathrm{CO}_{2}$ fertilization, stomatal control, PnET, fire cycles, soil expectation values, optimal economic rotation, adaptation

\section{RÉSUMÉ}

Nous explorons les effets des changements climatiques sur les rendements futurs des peuplements et sur les superficies qui seront brûlées, pour intégrer le tout afin de déterminer les valeurs futures de l'indice pédologique pour l'épinette blanche (Picea glauca (Moench) Voss) dans le centre de la saskatchewan. Les résultats laissent entendre que dans la plupart des scénarios envisagés, la productivité des peuplements s'accroît, mais décroît dans les cas d'extrême sécheresse. Toutefois, l'accroissement envisagé des superficies brûlées réduit ces accroissements de productivité. Dans le cas des hauts niveaux envisagés de superficies brûlées, les indices sont plus faibles qu’actuellement, ce qui entraîne un impact économique négatif. Nous avons également trouvé que le meilleur âge de rotation économique sous les climats à venir est inférieur à celui actuellement utilisé sous les conditions climatiques actuelles.

Mots clés : effets des changements climatiques, aménagement forestier, effets sur le rendement des peuplements, modèles des écosystèmes forestiers, apport de $\mathrm{CO}_{2}$ contrôle stomatale, valeurs des indices pédologiques, rotation économique optimale, adaptation

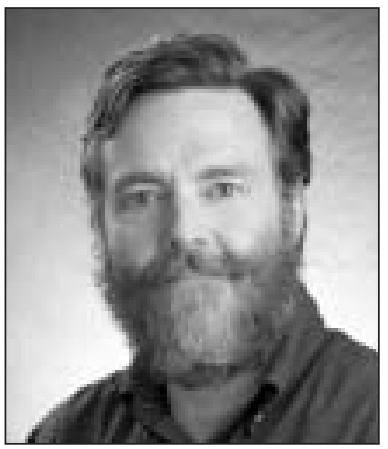

Mark Johnston

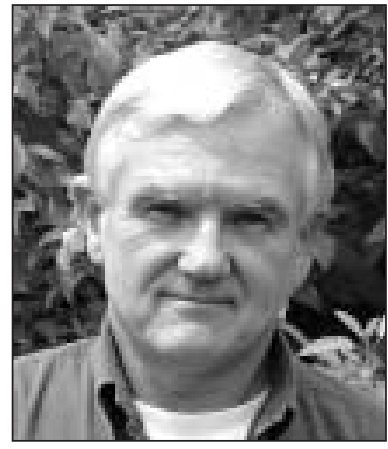

Tim Williamson

\section{Introduction}

Climate change will have a number of implications for future timber stand yields and land values. Some effects such as longer growing seasons and increased atmospheric carbon dioxide $\left(\mathrm{CO}_{2}\right)$ concentrations have the potential to result in enhanced growth. Other factors, such as increased drought frequency and intensity, inability of trees to adjust to changes

in their environment, regeneration failure, increased forest fire activity, and potentially higher rates of insect and disease attacks may have negative impacts on yields and timber supplies (Climate Change Impacts and Adaptation Directorate 2002, Spittlehouse and Stewart 2003, Ohlson et al. 2005). Climate change may also have a dampening effect on prices of forest products in global markets due to higher growth rates and increased supply, particularly in developing countries (Sohngen and Sedjo 2005). These factors are the drivers that will lead to changes in forest structure and productivity at local levels and to changes in the economic benefits that forests provide. Ultimately, it will also lead to changes in how forests are managed.

Forest management is long-term. Forest planning typically involves projections of forest yields and harvests over long planning horizons (e.g., 200 years or more). However, the analysis that supports long-term forest planning typically does not consider changes in future growing conditions that may be associated with climate change. Current wood supply analysis tools are not capable of incorporating changes in environmental conditions when determining forest growth and yield (Battaglia et al. 2004). Given the long-term nature

\footnotetext{
${ }_{1}^{1}$ Saskatchewan Research Council, 15 Innovation Blvd., Saskatoon, Saskatchewan S7N 2X8. E-mail: johnston@src.sk.ca ${ }^{2}$ Natural Resources Canada, Canadian Forest Service, 5320 - 122 Street, Edmonton, Alberta T6H 3S5. E-mail: Tim.Williamson@nrcanrncan.gc.ca
} 


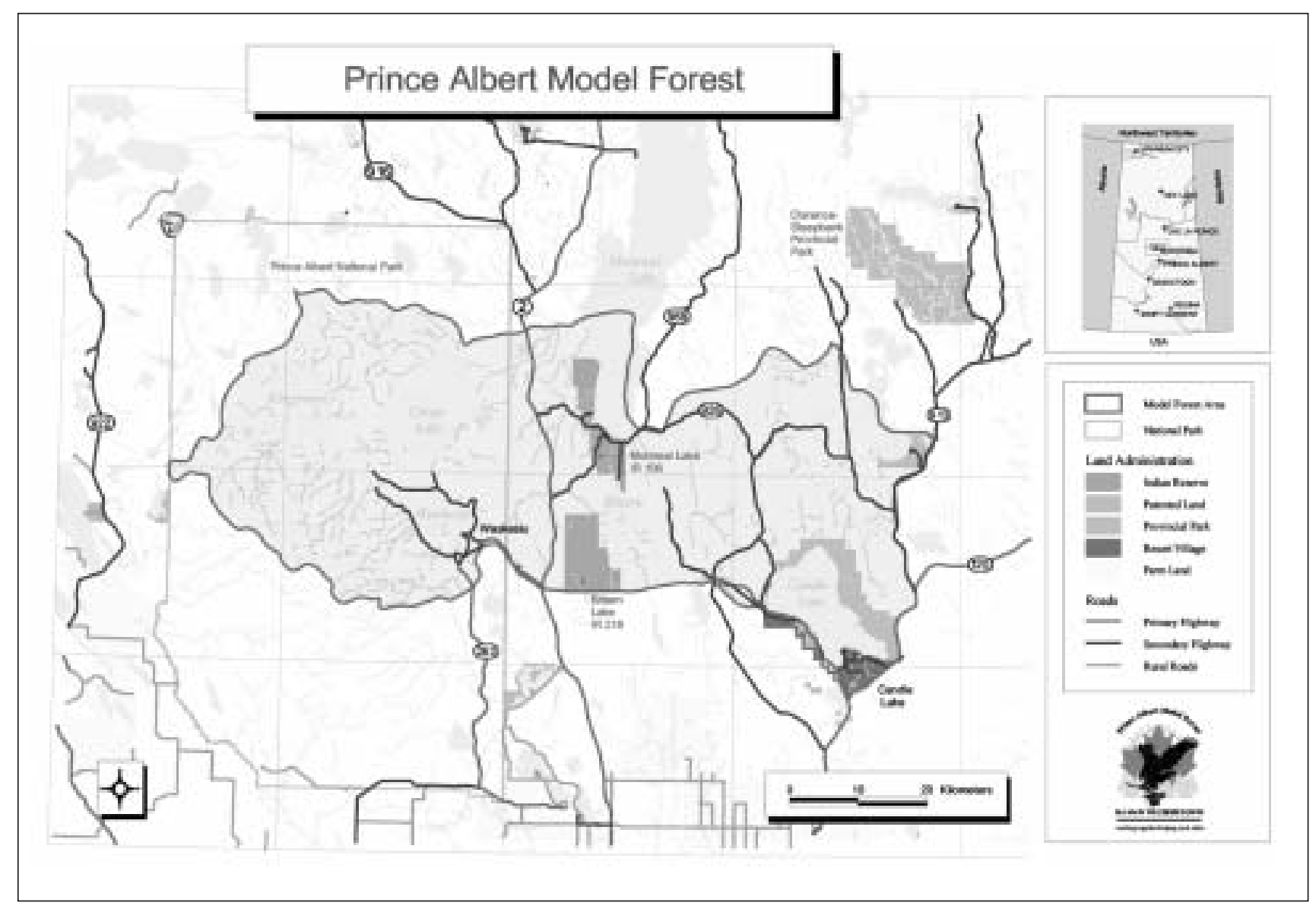

Fig. 1. Map of the Prince Albert Model Forest area.

of forest management planning and forest investments it is important that forest managers begin to give consideration to potential climate effects in long run planning (Spittlehouse and Stewart 2003). It is also important to include the longterm impacts of climate change into decision-making in general and to begin to think about implementing early adaptation measures. However, before such considerations are possible, more information regarding the combined effects of the various and potentially offsetting climate change factors needs to be generated. Moreover, this information is required at both the stand levels (e.g., yield responses, effects on land values) as well as at the broader landscape levels (e.g., timber supply changes, shifts in ecozones, regional economic impacts, etc.). In fact, policy-relevant analysis at higher levels is in some ways dependent on understanding local level impacts (i.e., stand level effects).

This study concentrates on the implications of climate change for future forest yields, optimal economic rotation and land values (or Soil Expectation Values, SEV). These measures are typically considered to be stand level measures. The analysis focuses on three areas. First, we consider climaterelated factors that will influence the future productivity of forest stands, and use a forest ecosystem model (PnET) to investigate impacts of climate change on future forest productivity. Second, we draw on recent research on future area burned under climate change and compare these results with current information about area burned in north central Saskatchewan. Third, we incorporate projected changes in yield and area burned into Reed's (1984) fire risk adjusted SEV formula. This formula provides an ability to not only look at the potential economic impacts of climate change in terms of impacts on forest land values but also provides insights into the implications of climate change on optimal economic rotation.

\section{Methods}

\section{Forest productivity}

The study area was generally the Prince Albert Model Forest (PAMF) area, approximately $75 \mathrm{~km}$ north of Prince Albert, Saskatchewan (Fig. 1). This area includes both protected forest (Prince Albert National Park) and managed forest (Weyerhaeuser's Forest Management Agreement area). It contains a variety of forest types including jack pine (Pinus banksiana Lamb), aspen (Populus tremuloides Michx.), aspenspruce mixedwoods and lowland areas dominated by black spruce (Picea mariana (Mill.) BSP). We chose to focus on white spruce in this analysis due to its commercial importance and the availability of data on physiology required by PnET.

Current and future climatic data were taken from the Canadian Regional Climate Model, Version 2 (CRCM II, Laprise et al. 2003). Data from CRCM is available for three 10-year time periods: 1975-1984 (current or $1 \times \mathrm{CO}_{2}$; 2040-2049 $\left(2 \times \mathrm{CO}_{2}\right)$ and 2080-2089 $\left(3 \times \mathrm{CO}_{2}\right)$. We used output for 2080-2089 in order to be consistent with Flannigan et al.'s (2005) analysis of future area burned (see below). The CRCM incorporates the GHG emissions scenario IS92a, 
which yields an atmospheric $\mathrm{CO}_{2}$ concentration of $642^{3}$ ppmv averaged over the 2080-2089 time period (the current $\mathrm{CO}_{2}$ concentration is about $380 \mathrm{ppmv}$ ). CRCM model output provides monthly values of (among others) precipitation, and mean minimum and maximum temperatures on a $45 \times 45$ $\mathrm{km}$ grid across western North America. Data for these three variables were collected for each of the nine CRCM grid cells that overly the PAMF area. The average value for each variable among the nine grid cells was calculated and used as input to the forest productivity model. In this way we attempted to capture a representation of climatic conditions over several grid cells rather than using data from a single cell.

We explored the accuracy of the CRCM climate data by comparing model output for the current period (1975-1984) to the observed climate record for Prince Albert for the same time period. Generally, mean maximum temperature was in close agreement, but modeled mean minimum temperatures were warmer that those observed. To remedy this, the mean annual difference between modeled and observed temperature was subtracted from each monthly modeled value. For mean maximum temperatures, the change was between 1 and 3 degrees, while that for mean minimum temperatures was between 2 and 5 degrees. Modeled precipitation was generally higher than that observed, so we adjusted the CRCM values by applying the ratio of observed to modeled annual precipitation to the modeled values; the ratio ranged from 0.6 to 1.1. The adjustments to temperature and precipitation were then applied in the same way to the CRCM data for 2080-2089. For the drought scenario, we compared the longterm normal precipitation for the 1961-1990 period for Prince Albert with that from a recent (2001-2003) drought in the same area. We found that during the drought, precipitation was about $60 \%$ of normal. We applied this factor to the CRCM data and generated a separate set of climate inputs with this reduced precipitation applied to all of the years in the 2080-2089 period. While this is clearly an extreme drought event, recent paleoclimate research has shown that such decade-scale droughts have occurred in Saskatchewan in the past (Sauchyn et al. 2004).

In order to project forest productivity into the future, we used a forest ecosystem simulation model that is sensitive to climate and other environmental factors (PnET, Photosynthesis and Evapo-Transpiration, Aber et al. 1997). The model has been widely tested across North America (see the PnET Web site for extensive documentation of model applications-http://www.pnet.sr.unh.edu). The model provides estimates of net primary productivity (NPP, g of biomass $\mathrm{m}^{-2} \mathrm{yr}^{-1}$ ) based on inputs of climate, species physiology and soil conditions. NPP expresses the gross production of biomass by trees not including litterfall and stem mortality. The CRCM data provided the climatic inputs, while most of the physiological data were taken from PnET calibration data for the spruce-fir forest type in the northeastern US (Aber et al. 1997). However, the model is particularly sensitive to foliar nitrogen content so we used local data for white spruce from

\footnotetext{
${ }^{3}$ This value represents an increase of about 1.8 times over that of 1975-1984. It is referred to as a $3 \times \mathrm{CO}_{2}$ scenario because the CRCM also includes the warming effect of other GHGs such as methane and nitrous oxide. Collectively these GHGs result in a $3 \times$ radiative forcing in the 2080-2089 time period relative to that in $1975-1984$
}

the BOREAS study carried out in the Prince Albert area from 1994-1998 (Newcomer et al. 2000). Another key input is soil available water-holding capacity (AWC). For soils data we used a recently collected data set from the Agriculture and Agrifood Canada Land Resources Centre at the University of Saskatchewan (G. Padbury, personal communication). These data comprise detailed soil survey information for a large portion of the forested area of Saskatchewan collected between 2002 and 2005 . We found that $67 \%$ of white sprucedominated stand types occurred on soils with AWC values in the range of 110-200 $\mathrm{mm}$, and chose the upper end of the range $(200 \mathrm{~mm})$ to represent conditions for optimum growth. These data also showed that $12 \%$ of white sprucedominated stands occurred on soils with less than $60 \mathrm{~mm}$ water-holding capacity. Therefore, we used a value of $50 \mathrm{~mm}$ in association with the drought simulation to represent extreme conditions of low moisture availability.

The model provides a number of options for considering the effects of $\mathrm{CO}_{2}$ on growth and water-use efficiency. The user can fix the level of $\mathrm{CO}_{2}$ for an individual model run, or let the model vary the $\mathrm{CO}_{2}$ concentration according to the rate of change of $\mathrm{CO}_{2}$ concentration measured in Mauna Loa, Hawaii (CDIAC 2003). In addition, the effect of $\mathrm{CO}_{2}$ on controlling stomatal opening and the associated increase in water use efficiency (Medlyn et al. 2001) can be turned on or off. Water use efficiency represents the amount of carbon gain per unit of water lost through transpiration. At higher levels of $\mathrm{CO}_{2}$, leaf carbon uptake is more efficient, thereby limiting water loss through the stomata (see Long et al. 2004 for a recent review of the effects of rising $\mathrm{CO}_{2}$ on plant growth). This option is available in PnET to recognize uncertainty in the current literature regarding the magnitude of this effect on tree growth under real field conditions (Ollinger et al. 2002).

In order to determine the validity of the model outputs, we tested the model estimates of NPP against the provincial yield curve for white spruce (Saskatchewan Environment 2001). In PnET, separate estimates of NPP are produced for foliage, wood and fine roots. Wood includes stem wood, branch wood and coarse roots. We converted total wood NPP estimates to stem wood NPP by subtracting the proportion of branch and coarse root biomass. The proportion of branch wood was taken from the recent CFS biomass inventory (Penner et al. 1997) using the data for white spruce in Saskatchewan. The proportion of coarse root biomass was determined from total biomass using the aboveground to belowground ratios for softwood species given in Li et al. (2003). For specific gravity of white spruce wood we used a value of $0.404 \mathrm{Mg} \mathrm{m}^{-3}$ (Gonzalez 1990). We found that the peak CAI for white spruce from the yield curve was $4.2 \mathrm{~m}^{3} \mathrm{ha}^{-1}$ $\mathrm{yr}^{-1}$, while that estimated by PnET was $3.8 \mathrm{~m}^{3} \mathrm{ha}^{-1} \mathrm{yr}^{-1}$.

While this agreement was strong, we used the relative change in productivity rather than the absolute change in comparing current with future productivity levels. This was accomplished by determining the ratio of future to current modeled NPP values and multiplying the current yield curve by this ratio. We made the simplifying assumption that allocation does not change with a change in NPP. In this fashion we developed yield curves for each of the future scenarios and used them in the subsequent analysis described below. The productivity scenarios included the following variations:

- Baseline: White spruce on $200 \mathrm{~mm}$ AWC soils with $\mathrm{CO}_{2}$ at current (1975-1984) levels (340 ppmv), no drought; 
- Future productivity for white spruce on $200 \mathrm{~mm}$ AWC soils with $\mathrm{CO}_{2}$ levels according to the IS92a levels (642 ppmv), no drought, stomatal response turned off;

- Future productivity for white spruce on $200 \mathrm{~mm}$ AWC soils with $\mathrm{CO}_{2}$ levels according to the IS92a levels (642 ppmv), no drought, stomatal control turned on;

- Future productivity for white spruce on $200 \mathrm{~mm}$ AWC soils with $\mathrm{CO}_{2}$ levels according to the IS92a levels (642 ppmv), with drought, stomatal response turned off;

- Future productivity for white spruce on $200 \mathrm{~mm} \mathrm{AWC}$ soils with $\mathrm{CO}_{2}$ levels according to the IS92a levels (642 ppmv), with drought, stomatal control turned on;

- Future productivity for white spruce on $50 \mathrm{~mm}$ AWC soils with $\mathrm{CO}_{2}$ levels according to the IS92a levels (642 ppmv), with drought, stomatal response turned off;

- Future productivity for white spruce on $50 \mathrm{~mm}$ AWC soils with $\mathrm{CO}_{2}$ levels according to the IS92a levels (642 ppmv), with drought, stomatal control turned on.

\section{Future area burned}

Flannigan et al. (2005) used General Circulation Model (GCM) output from the Canadian GCM, version 1 for 2080-2100 and the UK GCM (HadCM3GGa1) for 20802099 in calculating future area burned. This was accomplished by developing relationships among area burned by ecozone, the Canadian Fire Weather Index (FWI) system and current climatic data. These relationships were projected forward by substituting the GCM data for the current climate and recalculating components of the FWI. For the Boreal Plains ecozone (which contains the PAMF study area), results using the Hadley GCM indicate that area burned could increase by about 9\%, while results from the Canadian GCM showed an increase of about $245 \%$. These values were used in the SEV analysis described below.

\section{Soil expectation value}

Faustmann's formula is the basis for assessing the value of land in forest production (Buongiorno 2001). The Faustmann model measures the soil expectation value (SEV) of forestland. Soil expectation value represents the present value of net revenues obtained from a perpetual series of forest rotations. The value of time (T) that maximizes SEV is the optimal economic rotation. The deterministic version of the Faustmann formula is provided in Equation 1.

$$
S E V_{\text {*ut }}=\frac{\left(p^{*} V(T)-C\right) e^{-d T}}{1-e^{-\partial T}}
$$

Where:

$S E V_{\text {wof }}$ : Soil expectation value without fire

p: stumpage price - $\$$ per cu. $m$

$\delta$ : Assumed discount rate (e.g. $4 \%$ discount rate $=0.04$ )

$V(T)$ : Stand volume at time $\mathrm{T}$ - cu. $\mathrm{m}$. per ha

C: Reforestation cost - \$ per ha

T: Time (age of stand at harvest in years)

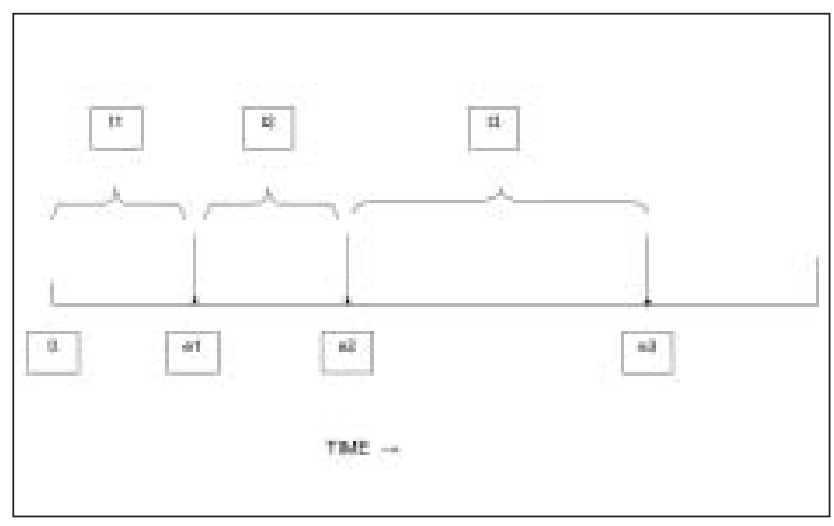

Fig. 2. A representation of random fire events and intervening time periods (where e1, e2, and e3 are random events and $\mathrm{t} 1$, t2, and $\mathrm{t} 3$ are time periods between events).

Reed (1984) extended the basic deterministic Faustmann model to account for fire risk. Reed's formula (obtained from Conrad and Clark 1999) for deriving the soil expectation value of a forest site under fire risk is shown in equation 2 .

$$
E\left[S E V_{* j}\right]=\frac{(\lambda+\delta)(V(T)-C) e^{-(\lambda+\delta) t}}{\delta\left(1-e^{-(\lambda+\delta) T}\right)}
$$

Where:

$E\left[S E V_{w f}\right]:$ Expected soil expectation value with fire $\lambda$ : hazard parameter

Other peramaters are as defined for equation 1

The hazard parameter $(\lambda)$ is obtained from a hazard function. Hazard functions can be used to assess the effects of climate change on wildfire risk. These are simple functions that describe the probability of some type of destructive event occurring (or not occurring) over some predetermined time interval. The inherently stochastic nature of wildfire means that the number of fires over a time interval and the period of time between fires are random (Fig. 2). These random variables are represented by statistical distributions. In the case of wildfire, previous studies have assumed that the number of fires over some interval follows a Poisson distribution (Reed 1984). Under this assumption, the time period between events has an exponential distribution (Evans et al. 2000).

The specific form of the cumulative hazard and survival functions for exponential distributions are as follows. The cumulative hazard function is defined as: $\mathrm{F}(\mathrm{T})=1-\exp ^{-}{ }^{\lambda T}$. $\mathrm{F}(\mathrm{T})$ is the cumulative probability of a destructive wildfire occurring over some time span (T), and $\lambda$ is the hazard rate. The survival function (i.e., the probability that a stand will be available for harvest after T years) is exp- ${ }^{\lambda T}$ (Reed 1984). The hazard rate for exponential distributions is simply $\lambda$ (or the probability of a fire in any given year, i.e., one divided by the fire cycle).

For this analysis we start by estimating the probability of survival under current conditions. A recent study by Parisien et al. (2004) found that fire cycles in central Saskatchewan 


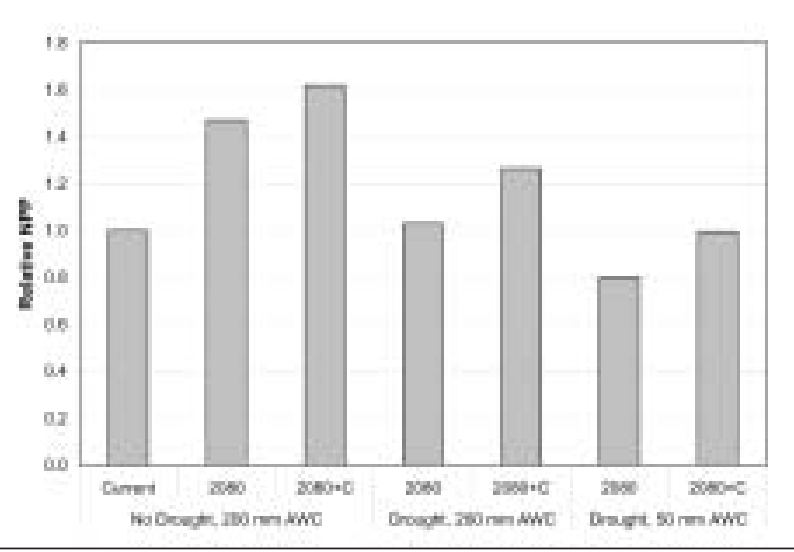

Fig. 3. White spruce net primary productivity simulated by $\mathrm{PnET}$ for Prince Albert under various scenarios, shown as values relative to current NPP. "+C" indicates scenarios in which the effect of increased water use efficiency was included

range from 263 to 288 . The corresponding values for $\lambda$ are 0.0038 and 0.0035 . For this study we adopted the higher value of 0.0038 as the baseline value for lambda under the current fire regime.

The next task is to determine a possible range of future values of $\lambda$. We used Flannigan et al.'s (2005) estimates of 9\% and $245 \%$ increase in area burned. These values suggest a general increase in area burned but also a high degree of uncertainty regarding the range of future burn rates in the region. Applying the predicted relative changes to the baseline value for $\lambda$ provides two new values for burn rates: 0.004 and 0.01311 . These values can be used to define an upper and lower boundary for burn rates in northern Saskatchewan in the 2080s.

\section{Results}

\section{Forest productivity}

Fig. 3 shows the predicted productivity levels for the future scenarios for white spruce, relative to those under the current climate. On sites with adequate moisture and no drought, productivity increases by about $40 \%$ in the absence of increased water use efficiency (WUE), and by $60 \%$ where WUE is increased. Under drought conditions on $200 \mathrm{~mm}$ AWC soils, productivity only increases when the WUE effect is included. On $50 \mathrm{~mm}$ AWC soils without increased WUE, productivity declines by $20 \%$ relative to current levels, and remains about the same when the WUE effect is included.

The values for each scenario shown in Fig. 3 were applied to the provincial white spruce D-density yield curve, resulting in a group of modified curves shown in Fig. 4. These were then used in the SEV analysis shown below.

\section{Soil expectation value}

As noted, climate change will affect both yield and disturbance frequency on forest lands. Both of these will affect the inherent value of land when that land is used for forestry production.

Table 1 provides the soil expectation values for northern Saskatchewan spruce stands under both current climate and climate conditions that may prevail in the 2080s. These results are based on equation 2 . The data and analytical assumptions that underlie the results are as follows. First, fire burn rates $(\lambda)$

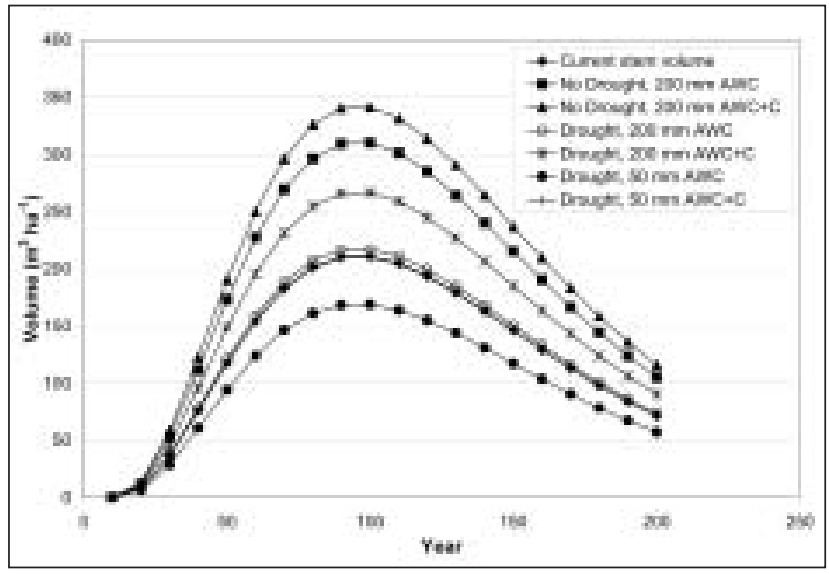

Fig. 4. Current and modified yield curves for D-density white spruce stands in the Prince Albert Model Forest area.

and discount rates $(\delta)$ are assumed to be constant over time. Second, a constant real stumpage price is assumed. The stumpage price for white spruce in Saskatchewan is assumed to be $\$ 25$ per cubic meter based on an assumed cash value of $\$ 15$ per cubic meter plus $\$ 10$ per cubic meter to account for costs incurred by leaseholders in return for harvesting rights. Reforestation costs are assumed to be $\$ 1750$ per ha and are assumed to be a current cost of harvesting. Therefore, reforestation costs are deducted from stumpage value at the time of harvesting as opposed to discounting future revenues and comparing these to current reforestation costs. In general, the decision to reforest a harvested stand is not based on economic criteria. Rather, companies operating on public lands are required to reforest all sites. The assumed discount rate for this analysis is $4 \%$.

There are five main findings that are evident from the results provided in Table 1. First, an increase in burn rates reduces SEV. Second, the optimal economic rotation under future climatic conditions is generally lower than that under present conditions. Third, the results regarding the economic impact of climate change are ambiguous. It is clear that there is some potential for economic gains through higher productivity but these effects are offset by higher fire risk. Fourth, the impacts of climate change are very sensitive to site conditions. For example, if moisture becomes limiting under future climates then forestland values for sites with low water holding capacity could significantly decrease. Thus, climate change may be beneficial on some sites and very costly to the value of other sites. Fifth, the assessment of net impacts depends on assumptions regarding adaptive response of both trees and land managers. For example, productivity gains are in some respects dependent on the ability of trees to take advantage of $\mathrm{CO}_{2}$ fertilization and their ability to become more efficient in their use of water. Economic gains are dependent on the willingness of forest managers to adjust harvest ages. These results are discussed further in the next section.

\section{Discussion and Conclusions}

Although this study evaluates some of the ways that climate change may affect forest yields and land values, additional factors were not considered. For example, it has been suggested that if climate change results in climatic conditions that exceed the genetically programmed physiological tolerances of specific genotypes then reduced growth or mortality of 
Table 1. Soil expectation values under the scenarios shown in Fig. 1 and two levels of fire probability. Values in bold indicate the highest SEV for a given scenario

\begin{tabular}{|c|c|c|c|c|c|c|c|c|c|c|c|c|c|c|}
\hline & \multicolumn{14}{|c|}{ Scenario } \\
\hline & 1 & 2 & 3 & 4 & 5 & 6 & 7 & 8 & 9 & 10 & 11 & 12 & 13 & 14 \\
\hline Drought & & & No & No & No & No & Yes & Yes & Yes & Yes & Yes & Yes & Yes & Yes \\
\hline Soil WHC & & & 200 & 200 & 200 & 200 & 200 & 200 & 200 & 200 & 50 & 50 & 50 & 50 \\
\hline WUE effect & & & No & No & Yes & Yes & No & No & Yes & Yes & No & No & Yes & Yes \\
\hline Climate and $\mathrm{CO}_{2}$ & \multicolumn{2}{|c|}{ Current } & 2080 & 2080 & 2080 & 2080 & 2080 & 2080 & 2080 & 2080 & 2080 & 2080 & 2080 & 2080 \\
\hline $\begin{array}{l}\text { Lambda } \\
\text { (fire rate) }\end{array}$ & 0 & 0.0038 & 0.004 & 0.0131 & 0.004 & 0.0131 & 0.004 & 0.0131 & 0.004 & 0.0131 & 0.004 & 0.0131 & 0.004 & 0.0131 \\
\hline Age & \multicolumn{14}{|c|}{ Soil expectation values } \\
\hline 40 & 38.0 & 34.5 & 240.0 & 189.2 & 302.9 & 238.8 & 45.7 & 36.0 & 148.6 & 117.1 & 0.0 & 0.0 & 34.3 & 27.0 \\
\hline 50 & 187.8 & 165.6 & 353.0 & 258.4 & 414.6 & 303.5 & 174.8 & 127.9 & 270.7 & 198.2 & 82.2 & 60.2 & 161.1 & 117.9 \\
\hline 60 & 212.0 & 181.1 & 333.9 & 226.0 & 380.4 & 257.5 & 188.1 & 127.3 & 266.3 & 180.2 & 114.1 & 77.2 & 177.5 & 120.2 \\
\hline 70 & 182.9 & 151.2 & 263.6 & 164.4 & 299.4 & 186.8 & 157.7 & 98.3 & 213.3 & 133.0 & 102.0 & 63.6 & 148.4 & 92.6 \\
\hline 80 & 140.2 & 112.1 & 189.6 & 108.7 & 214.7 & 123.1 & 114.9 & 65.9 & 155.2 & 89.0 & 76.3 & 43.8 & 109.9 & 63.0 \\
\hline 90 & 98.3 & 75.9 & 128.3 & 67.5 & 144.8 & 76.2 & 78.6 & 41.3 & 104.8 & 55.1 & 52.4 & 27.6 & 74.3 & 39.1 \\
\hline 100 & 65.8 & 49.0 & 82.0 & 39.5 & 92.6 & 44.6 & 50.3 & 24.2 & 67.3 & 32.4 & 33.8 & 16.3 & 47.9 & 23.1 \\
\hline 110 & 42.0 & 30.1 & 50.6 & 22.3 & 57.4 & 25.3 & 30.9 & 13.6 & 41.4 & 18.3 & 20.6 & 9.1 & 29.4 & 13.0 \\
\hline 120 & 25.7 & 17.8 & 30.3 & 12.2 & 34.4 & 13.9 & 18.3 & 7.4 & 24.6 & 9.9 & 12.0 & 4.8 & 17.3 & 7.0 \\
\hline
\end{tabular}

individual trees or their regenerated offspring may occur, even if overall growing conditions become more favourable. Thus, realization of potential productivity increases may depend on our ability to reforest sites using trees selected from different regions where the current climate is similar to that expected in the future. In addition, trees will eventually adjust to new climatic conditions through evolutionary adaptation (Rehfeldt et al. 1999). Another factor that we have not considered is the possibility that non-climatic factors may limit productivity gains. For example, Liu et al. (2005) suggest that nitrogen may be a limiting factor inhibiting productivity gains from climate change in the boreal forest.

A further simplification is that we have assumed a constant real price for white spruce stumpage over time. A more realistic assumption would be to consider price as a non-stationary random variable. We do not, however, have any valid basis for making assumptions about the degree of variance in future price or in the magnitude of changes in expected values over time. The main implication of this is that although these results provide some useful preliminary understanding of climate effects on forest yield and land values, there is some uncertainty in the results presented.

The uncertainty inherent in our results is not unique. In fact, uncertainty is a defining feature of climate change impact studies. There are numerous sources of uncertainty in climate impact analysis. Previous studies have attempted to capture uncertainty in climate impacts assessment using different combinations of emissions scenarios, climate models and response models (e.g., Irland et al. 2001, Nabuurs et al. 2002). In this study we have changed this perspective by holding variability from these sources constant and instead focused on how the results vary under different assumptions regarding a) tree response, b) soil characteristics, c) drought effects, and d) fire disturbance effects. The uncertainty revealed in this study will be even greater when considering ranges of effects under different emission scenario assumptions and climate model predictions.
A change in risk and uncertainty resulting from climate change has important implications for forest management. Increases in risk and uncertainty suggest the need to change from managing forest resources deterministically to managing resources with uncertainty reduction and risk management as specific objectives. The particular properties, characteristics and features of local forest management systems will influence the capacity of forest managers to manage risk. Three general system properties will be important. First, the forest management system will need to be flexible (Montgomery 1996). Second, the range of technologies used within the system and outputs produced by the system should be as diverse as possible. Third, the forest management system should permit adaptive management (Montgomery 1996).

Two important questions that will have a bearing on the how much adaptive risk management actually occurs in response to climate change are as follows:

1. Is climate risk relevant in a local forest management context?

2. If risk management is relevant, who has the most at stake and therefore is most likely to pursue strategies to manage risk?

To answer the first question it is useful to start with a definition of risk. In general terms, risk is the potential or likelihood of a detrimental impact. The analysis in this paper suggests that there is the potential for a detrimental impact, even though productivity might increase on average. Therefore, risk and risk management are relevant in a local forest management context. However, if the scenarios analyzed here had suggested higher land values over the full range of potential outcomes, the implications for forest management would probably not be considered as risk management. Rather the appropriate management strategy would be to implement adaptations that maximize climate benefits.

The second question pertains to the identification of who has the most to gain by managing risk and who, therefore, is most likely to want to pursue a risk management approach. 
The two groups that would be expected to be concerned about uncertainty and risk are provincial forest management agencies and forest product companies. However, in general (with some exceptions) they have not, to date, expressed a great deal of concern about climate change and have not expressed significant interest in modifying forest management systems to manage climate risk. There are a number of potential explanations for this general indifference. First, it may be that these two groups have in some way made an assessment of the risks related to climate change and have concluded that there is presently insufficient basis to conclude that risks will be significant. A second potential reason is that there is insufficient (and in some cases conflicting) information about possible future impacts. There simply may be too much uncertainty at this stage about future effects to justify making radical changes in forest policy and management. This seems like a classic Catch 22, i.e., there is too much uncertainty to justify modifying forest management but it is the increase in uncertainty that is calling for modification to forest management. The high level of uncertainty, however, should not be an excuse for doing nothing. There are a number of different ways to address uncertainty and manage risk. For example, possibilities include: (a) targeted research and learning, (b) improved data and information sharing, (c) encouraging experimentation and adaptive management in forest management and planning, (d) investigating new kinds of institutional arrangements that are more effective at facilitating autonomous adaptation (e.g., is there a potential larger role for private markets in forest management in Canada?), (e) reducing exposure through hedging, diversification and/or shorter rotations, and (f) risk reduction strategies such as fire-smart landscapes (Hirsch et al. 2001). Possibly the most significant change that needs to occur is that forest managers will need to recognize and embrace the increasing levels of uncertainty that are anticipated to occur.

\section{Acknowledgements}

We thank Rita Freuder and colleagues with the PnET development team at the University of New Hampshire for pointers to parameter values, and Mike Flannigan (Canadian Forest Service) for assistance with CRCM data. Data from the BOREAS project was supplied by the Oak Ridge National Laboratory's Distributed Active Archive Center for Biogeochemical Dynamics. Greg O’Neill (B.C. Ministry of Forests) and Pierre Bernier (Canadian Forest Service) provided valuable comments on an earlier draft of the paper. MJ was supported by funding from the Prince Albert Model Forest.

\section{References}

Aber, J.D., S.V. Ollinger, C.A. Federer and C. Driscoll. 1997. Modeling nitrogen saturation in forest ecosystems in response to land use and atmospheric deposition. Ecological Modelling 101: 61-78.

Battaglia, M., P. Sands, D. White and D. Mummery 2004. CABALA: a linked carbon, water and nitrogen model of forest growth for silvicultural decision support. Forest Ecology and Management 193: 251-282.

Buongiorno, J. 2001. Generalization of Faustmann's formula for stochastic forest growth and prices with Markov decision process models. Forest Science 47: 466-474.

Carbon Dioxide Information Analysis Center (CDIAC). 2003. Trends Online: A Compendium of Data on Global Change. Oak Ridge National Laboratory, U.S. Department of Energy, Oak Ridge, TN. Available at: http://cdiac.ornl.gov/trends/trends.htm
Climate Change Impacts and Adaptation Directorate. 2002. Climate impacts and adaptation: A Canadian perspective - Forestry. Climate Change Impacts and Adaptation Directorate, Natural Resources Canada, Ottawa.

Conrad, J.M. and C.W. Clark. 1999. Natural Resource Economics. Cambridge University Press, Cambridge, UK. 254 p.

Evans, M., N. Hastings and B. Peacock. 2000. Statistical distributions: Third edition. Wiley Series in Probability and Statistics, New York, NY. 248 p.

Flannigan, M.D., K.A. Logan, B.D. Amiro, W.R. Skinner and B.J. Stocks. 2005. Future area burned in Canada. Climatic Change (in press).

Gonzalez, J.S. 1990. Wood density of Canadian tree species. Forestry Canada Northern Forestry Centre Information Report NOR-X-315. Edmonton, $\mathrm{AB}$.

Hirsch, K., V. Kafka, C. Tymstra, R. McAlpine, B. Hawkes, H. Stegehuis, S. Quintilio, S. Gauthier and K. Peck. 2001. Fire-smart forest management: a pragmatic approach to sustainable forest management in fire-dominated ecosystems. The Forestry Chronicle 77: $1-7$.

Irland L., D. Adams, R. Alig, C. Betz, C.-C. Chen, M. Hutchins, B. McCarl, K. Skog and B. Sohngen. 2001. Assessing socio-economic impacts of climate change on US forests, wood-product markets, and forest recreation. BioScience 51: 753-764.

Laprise, R., D. Caya, A. Frigon and D. Paquin. 2003. Current and perturbed climate as simulated by the second-generation Canadian Regional Climate Model (CRCM-II) over northwestern North America. Climate Dynamics 21: 405-421.

Li, Z., W. Kurz, M. Apps and S. Beukema. 2003. Belowground biomass dynamics in the Carbon Budget Model of the Canadian Forest Sector: recent improvements and implications for the estimation of NPP and NEP. Canadian Journal of Forest Research 33: 126-136.

Liu, J., D.T. Price and J.M. Chen. 2005. Nitrogen controls on ecosystem carbon sequestration: a model implementation and application to Saskatchewan, Canada. Ecological Modelling 186: 178-195.

Long, S.P., E.A. Ainsworth, A. Rogers and D.R. Ort. 2004. Rising atmospheric carbon dioxide: plants FACE the future. Annual Review of Plant Biology 55: 591-628.

Medlyn, B., C. Barton, M. Broadmeadow, R. Cuelemans, P. DeAngelis, M. Forstreuter, M. Freeman, S. Jackson, S. Kellomaki, E. Laitat, A. Rey, B. Sigurdsson, J. Strassmeyer, K. Wang, P. Curtis and P. Jarvis. 2001. Stomatal conductance of forest species after long-term exposure to elevated $\mathrm{CO}_{2}$ concentration: a synthesis. New Phytologist 149: 247-264.

Montgomery, C.A. 1996. Risk and forest policy: Issues and recent trends in the U.S. Ecological Economics. 16: 65-72.

Nabuurs, G.-J., A. Pussinen, T. Karjalainen, M. Erhard and K. Kramer. 2002. Stemwood volume increment changes in European forests due to climate change - a simulation study with the EFISCEN model. Global Change Biology 8: 304-316.

Newcomer, J., D. Landis, S. Conrad, S. Curd, K. Huemmrich, D. Knapp, A. Morrell, J. Nickeson, A. Papagno, D. Rinker, R. Strub, T. Twine, F. Hall and P. Sellers. 2000. Collected Data of the Boreal Ecosystem-Atmosphere Study. CD-ROM. NASA-Goddard Space Flight Centre, USA.

Ohlson, D.W., G.A. McKinnon and K.G. Hirsch. 2005. A structured decision-making approach to climate change adaptation in the forest sector. The Forestry Chronicle 81: 97-103.

Ollinger, S.V., J.D. Aber, P. B. Reich and R. J. Freuder. 2002. Interactive effects of tropospheric ozone, nitrogen deposition, elevated $\mathrm{CO}_{2}$ and land use history on the carbon dynamics of northern hardwood forests. Global Change Biology 8: 545-562.

Parisien, M.A., K.G. Hirsch, S.G. Lavoie, J.B. Todd and V.G. Kafka. 2004. Saskatchewan Fire Regime Analysis. Information Report NOR-X-394, Northern Forestry Centre, Canadian Forest Service, Natural Resources Canada. Edmonton, AB. 61 p.

Penner, M., K. Power, C. Muhairwe, R. Tellier and Y. Wang. 1997. Canada's Forest Biomass Resources: Deriving Estimates from 
Canada's Forest Inventory. Information Report BC-X-370, Pacific Forestry Centre, Canadian Forest Service, Natural Resources Canada. Victoria, BC. 42 p.

Reed, W.J. 1984. The effects of risk of fire on the optimal rotation of a forest. Journal of Environmental Economics and Management 11: 180-190.

Rehfeldt, G. E., C.C. Ying, D.L. Spittlehouse, and D.A. Hamilton. 1999. Genetic responses to climate in Pinus contorta: niche breadth, climate change, and reforestation. Ecological Monographs 69:375-407.

Saskatchewan Environment. 2001. Provincial Yield Curves for Commercial Forest Species. Saskatchewan Forest Service, Saskatchewan Environment, Prince Albert, SK.
Sauchyn, D.J., E. Barrow, R.F. Hopkinson and P. Leavitt. 2004. Aridity on the Canadian Plains. Géographie physique et Quaternaire 56: $247-259$.

Sohngen, B. and R. Sedjo. 2005. Impacts of climate change on forest product markets : Implications for North-American producers. The Forestry Chronicle 81(5): 669-674.

Spittlehouse, D.L. and R.B. Stewart. 2003. Adaptation to climate change in forest management. BC Journal of Ecosystems and Management 4: 1-11. 